\title{
Circuit board accident - organizational dimension hidden by prescribed safety
}

\author{
Ildeberto Muniz de Almeida ${ }^{\mathrm{a}^{*}}$; Eduardo Buoso ${ }^{\mathrm{c}}$, Maria Dionísia do Amaral Dias ${ }^{\mathrm{a}}$, Rodolfo \\ Andrade Gouveia Vilela ${ }^{\mathrm{b}}$ \\ a Botucatu Medical School, UNESP - Univ Estadual Paulista, Botucatu Campus, Department of \\ Public Health \\ ${ }^{\mathrm{b}}$ School of Public Health Environmental Health Department, University of São Paulo (USP). \\ ${ }^{\mathrm{c}}$ Cerest Piracicaba
}

\begin{abstract}
This study analyzes an accident in which two maintenance workers suffered severe burns while replacing a circuit breaker panel in a steel mill, following model of analysis and prevention of accidents (MAPA) developed with the objective of enlarging the perimeter of interventions and contributing to deconstruction of blame attribution practices. The study was based on materials produced by a health service team in an in-depth analysis of the accident. The analysis shows that decisions related to system modernization were taken without considering their implications in maintenance scheduling and creating conflicts of priorities and of interests between production and safety; and also reveals that the lack of a systemic perspective in safety management was its principal failure. To explain the accident as merely non-fulfillment of idealized formal safety rules feeds practices of blame attribution supported by alibi norms and inhibits possible prevention. In contrast, accident analyses undertaken in worker health surveillance services show potential to reveal origins of these events incubated in the history of the system ignored in practices guided by the traditional paradigm.
\end{abstract}

Keywords: occupational accidents; accident prevention; accident investigation; surveillance system

\section{Introduction}

Recent years have seen growing criticism of accident analyses concluded in a matter that explains the occurrence as a product of worker error and, based on this, is held responsible for the event $[1,2,3]$.

This study presents an example of the investigation of an accident in which two maintenance workers suffered severe burns during replacement of a circuit breaker panel in a steel mill. The safety team of the company blamed the victims and the immediate supervisor involved in the case. This judgment served as a basis for punishment of these workers and firing of the supervisor.

The case was reviewed by the surveillance team of the Worker Health Reference Center (Cerest) applying the Model of Analysis and Prevention of Accidents (MAPA) [4] developed with the aim of enlarging the perimeter of interventions and contributing to the deconstruction of blame-attribution practices.
The study explores in-depth analysis of the accident as a potential source of resources for reflection on the experiences of implantation of strategies of health surveillance focused on the work accident. The main aim is to verify up to what point the new analyses contribute to enlargement of the perimeter of surveillance interventions. From a subsidiary manner the study seeks to explain: aspects of the event's origins that remain unrevealed in intervention in analyses elaborated by safety teams of companies, in particular those already denominated in the literature as latent conditions [5] or incubated origins [6] and misconceptions of the form as a traditional approach to accidents dealing with the human dimension in these occurrences. Thus is indicated the potential of interventions in relation to deconstruction of practices of blame attribution established in companies. 


\subsection{History and context of the initiative}

In Brazil, the Ministry of Health stimulates the development of worker health actions in all the services of the Single Health System. One of the strategies adopted to encourage this process is the creation of the Worker Health Reference Centers (Cerest) which performs activities for surveillance and attention, as well as support to their implementation in non-specialized services [7].

Cerest, active in the region of Piracicaba, in the state of Sao Paulo, routinely performs analyses of work accidents, prioritizing severe and fatal cases. In the last decade its surveillance team has participated in offering trainings and the development of instruments that aim to offer conceptual support to be used as a guide in conducting data collection and interpreting findings related to work accidents (WA).

After noting that companies with the highest accident indices in the territory also presented frequent conclusion of WA analyses that attribute blame to the victims, Cerest is stimulating the development of a model of analysis and prevention of accidents, MAPA, [4] which offers a path of systematization of investigation and the adoption of systemic explanations for the occurrence.

MAPA organizes this process into four principal steps to be developed in a participative manner to capture knowledge and viewpoints of workers that perform the activity in which the accident had occurred or of others who are related to it: a) description of normal work including variabilities associated with the accident and adjustments in strategies and operational modes; b) analyses of changes; c) analyses of barriers and; d) conceptual enlargement.

The analyses of changes and of barriers must explore the facts ranging from the identified departure point to the causes of causes, going beyond the approach of proximal aspects at the outcome of the accident. The findings from the former tend to be organized as failures of staff management, production times, maintenance, changes, projects, equipment conception, the coordination of successive or simultaneous activities, the provision of materials etc. and from the former in terms of failures in safety management.

The expression conceptual enlargement is utilized to stimulate the identification of aspects of the incident that could be better comprehended through concepts from diverse branches of knowledge that are already being employed in the analyses and studies of accidents. It utilizes contributions from ergonomics, of social, cognitive and work psychology, of systems engineering, social sciences, anthropology etc. Analysis teams are encouraged to know how to recognize situations that may benefit from conceptual rereadings and, to the extent possible, to know how to identify the most indicated concepts in each situation. At Cerest in Piracicaba the interaction with outside researchers potentiates the utilization of conceptual enlargement.

\section{Method}

This study is based on materials produced by the Piracicaba team of Cerest during in-depth analysis of the accident. This includes a final report, copies of documents supplied by the company, from interviews with workers and their supervisors in conformity with the steps of MAPA described above [4].

The materials were reviewed so as to highlight how the registers show the appropriation or lack thereof of the guiding concepts adopted in the model: description of real work, analysis of changes, analysis of barriers and conceptual enlargement. The rereading concentrates on the description and conclusions of the analysis as well as the prevention suggestions formulated from the findings.

\section{Results}

\subsection{The accident according to the analysis by the company}

Contrary to company norms, two electrical maintenance workers replaced an energized circuit breaker panel. In the attempt, the action of one of them provoked shock and an electrical arc that also reached a colleague who was at his side. The replacement was authorized by the area supervisor. This occurrence was explained as an unsafe act; the three workers were indicated as guilty, resulting in punishment of those involved.

\subsection{Analysis made by the Cerest surveillance team}

The initial approach aims to clarify the real work, as well as eventual changes in components or their interactions and barriers present in the system with the emphasis on aspects related to the accident.

Two maintenance workers were assigned to replace the breaker on a high-tension panel in the room of the roughing mill 1. As prescribed, 
the work was already scheduled to be performed during a production stoppage programmed daily at the peak hour for energy consumption. This form of labor organization is recognized by the maintenance teams as being associated with an increase in time pressure, since in the event of delays the workers would be held responsible.

The surveillance team knew that the breaker was shutting down the system. This fact was explained in the company as being due to "natural" wear whose origins had not been clarified. Clarification was solicited on the routines adopted in relation to time and the use of replacement scheduling for components of panels aiming to identify possible failures in the management of system maintenance.

Following company procedure the workers solicited permission from the area supervisor to initiate the replacement. Such permission was denied because the breaker replacement requires that the board be de-energized and, at that moment, the workers of the outside business finalized replacement of the control system of the roughing mill 1, demanding that it be powered up. Thus a third party was contracted to complete the already delayed system modernization. After the conclusion of the analysis, the Cerest analysis team took account of what was not explored: the form of payment defined in the contract and whether this would have contributed to the accident. When the payment is made as a function of the time that the third party remain in the business, this task tends to be prioritized and, if possible, done at an accelerated pace.

Without permission to perform the scheduled activity, the maintenance workers re-discussed the situation with the area supervisor that had authorized the replacement in a co-activity with the energized circuit board. The decision for the task was influenced by the following factors, among others:

- The supervisor has experience in automation, but not in maintenance;

- The system would be equipped with devices that would still permit the replacement to be performed safely;

- Interrupting the implantation of the automation system would delay its chronogram and re-initiation of production;

- Postponing the replacement of the breaker would increase the chances of a defect in the board and of consequent stoppage for correction;

- Delays in breaker replacement or in production via board failure could lead to punishment of the maintenance workers, through the productivity evaluation adopted in the business.
The electricians knew that with system energized it was not possible to use the grounding prescribed in the company's norms.

A detailed exploration of the sequence of operations performed revealed that the breaker brought by the workers was produced by a different manufacturer than the one installed and that the fitting of its three connectors had dimensions distinct from the previous one. The electrician only perceived the difference at the end of the replacement, when the part could not be installed.

Given the difficulty that was found, the worker decided to cut the connections to enable the fitting. To facilitate the realization of the fine movements demanded for this cut to increase its safety, the operador removed his isolating glove. After reducing the diameters of the two lateral connectors, to initiate the cut from the center, the cutting point of the tongs approached one of the rods, which was also energized, producing an electric arc and burns in the operator and his colleague.

The analysis of changes showed that the electrician would have already replaced the breakers in similar panels without encountering problems. And that it could be done again if the part that he received would be equivalent to removing it. The analysis team would want to know whether the available part was cheaper and also if it were common practice in the company to replace it with devices of a different brand from the one originally installed. Unfortunately, there was no collaboration that would permit clarification of the reasons associated with the availability of a breaker of a brand different from the one that would be replaced.

The Cerest team identified that the installation of a new roughing mill control was realized so that it configured asynchronic evolution of system components [9].

Furthermore, the substitution in the roughing mill 1 had been delayed at the end of the prior year because the company had seen an increase in sales during the period and could not have met the attendant demand if production had been stopped in the sector. However, there was no collaboration from the company to clarify whether the replacement was delayed, if those responsible for the decision to do it on the day of the accident were the same ones responsible for scheduling of maintenance nor if they considered the possibility of problems in safety management in the event of a co-activity situation. Also, it was not possible to know whether the company's safety team was informed that the tasks would be performed in a co-activity. 
The existent safety procedure did not consider situations of co-activity or variabilities such as that which the team faced.

\subsection{Changes demanded by the Cerest team}

The discussions on prevention proposals to be carried out in this case were given after the team discussion on the technical and participatory political difficulties felt about how to approach the organizational dimension in the negotiation proposed with the company. The following highlighted aspects reflect, therefore, a process in which the team counted on the expressed help of the outside researchers and in which part of the recommendations appeared after the release of the first version of the analytical report of the Cerest team. A participative process was adopted to formulate and validate suggestions for prevention.

One of the points of departure was the realization of meetings to validate the findings of the data collection, especially in reference to confirming: a) that the accident occurred during an attempt to cut the rods of the device connected to the breaker to be installed so as to permit it to fit properly; b) that the strategies adopted by the electrician to adjust the part from a different manufacturer and to intervene in an energized system, without or outside of a coactivity context, were practices already used previously by the workers, with success; c) that historically, in situations of conflicts between interests of production and safety, the workers knew that they should prioritize production. That despite the existence of the safety norms cited to justify the punishment of those involved, the company's historical pattern of favouring production at the expense of safety, has pressured the workers to perform the replacement.

Among other requests the Cerest team recommended reviewing the punishments decreed by the company, and following provisions, all in determinate timeframes: a) to present a list of measures to be adopted in order to improve safety in situations of asynchronous evolution of a system and of co-activity. The decisions taken in these cases must include a safety sub-system to evaluate risks resulting from interferences between the tasks and ways of improving coordination between the teams involved; b) to enumerate the most frequent situations of co-activity in the company and to recommend improvements in the coordination among those involved in the task; c) to enumerate situations in which the possibility of incompatibilities between materials introduced variabilities whose management increases the chances of accidents, as in the case of the breaker; to present a chronogram of the adoption of practices to standardize materials or alternative solutions; d) to initiate a process of discussion with all the workers, beginning with electrical maintenance, on the need to know how to recognize the safety frontiers of the system and implications for them in the event of changes in the strategies and operational modes used in the activity; e) to enumerate situations known to be the most likely to occur from predictable bypassing of steps of the task, to discuss their possible implications for system safety and to propose alternatives of improvements elaborated in a participative manner when appropriate [10]; f) to present an alternative proposal of safety management eliminating, in turn, policies and practices that adopt explanations of accidents as events centered on the person and adopting approaches supported by a systemic perspective that stimulate organizational learning; g) to organize a chronogram for presenting conclusions of the Cerest team analysis in the company including separate meetings with the Workplace Medicine and Safety Service team (Sesmt) ${ }^{1}$ and highranking representatives of the company, members of the Internal Commission for the Prevention of Accidents (CIPA) $)^{2}$ and an open meeting with the maintenance staff and the other workers, all with free access to labor union representatives.

\section{Discussion}

The intervention carried out by the Cerest team shows that the investigation conducted by the professionals of the company presented the accident as centered in operator errors when in fact it originated from a network of interacting factors.

In the studied case two workers suffered severe burns as a result of electric shock during an attempt to install an energized circuit breaker panel of a brand different from the one that had been removed on account of presenting a defect.

The network of factors whose interaction led to the accident included in its origins the immediate decisions of the supervisor, of permitting work on an energized panel and, of the electricians, of not grounding the panel and not interrupting the replacement initiated after

\footnotetext{
${ }^{1}$ Service of the company, as provided in Brazilian labor law.

2 Commission of workers, elected by peers and indicated by the company, as provided in Brazilian labor law.
} 
discovering, at the end of the task, the inadequacy of the materials.

In the origins of the aforementioned decisions it was possible to identify a conflict between the interests of production and safety, resulting from a co-activity situation in which the modernization of the roughing mill 1 impeded a previously scheduled maintenance task. Also contributing to the decisions was the fact that before the initiation of the replacement the electricians did not perceive that they had received a breaker of a different brand than the one they had needed to replace; further more he had knowledge of the historically adopted practices of bypassing the safety procedures to benefit production. These aspects show that the non-fulfillment of safety norms is not sufficient to explain the origins of the accident. In this type of situation the main challenge is clarify for what reasons some practices adopted with success in the past failed on this occasion. Reducing the event to mere non-fulfillment of the rules should imply a loss of opportunity for learning about the real work and for the enlargement of the perimeter of prevention interventions in the company.

MAPA's analysis also highlights some aspects of the origins of the accident that deserve further discussion, such as:

a) dealing, in the course of action already initiated, with a situation unanticipated in the plan that guided the action. This occurs when the electrician finds that the breaker he wanted to install was of a different brand from the one being replaced.

b) dealing with conflicts between safety and production.

The approach of these aspects from a formal safety perspective in the analysis of representatives of the company is superficial and based on equivocal presuppositions about what governs human behaviors in a work situation.

In an accident situation an action takes place in the context of increasing the time pressure associated with delay in initiating the task, with impediments to the adoption of safety practices, knowledge of the existence of a threat associated with the current evaluation system, the use of inadequate resources being discovered only at the end of the task, knowing it is possible to rapidly conclude the task with the chosen strategy. All of this appears to coexist with uncertainty as to the existence of a breaker of the same brand as the one being replaced.

Formal safety prefers to adhere to an idealized vision of what the work would be, concluding its analysis in a manner that inhibits prevention, a perspective that holds safety, contrary to our findings, to be the highest organizational value.

\section{Conclusions}

Analyses of accident realized in the routines of worker health surveillance services are shown to be potential revealers of the origins of these events incubated in the history of the system and ignored in practices guided by the traditional paradigm.

The identification of latent conditions of accidents is aided by the use of guiding concepts of collection and interpretation of data, but requires the collaboration of workers that know the real work. Fears associated with the possibility of legal liability for what happened and the safety management practices that encourage the attribution of blame victims tend to hamper the reconstruction of the accident. The adoption of practices to validate the findings of the analysis is revealed as an important strategy for minimizing conflicts over the conclusions of the analyses.

Interventions that seek to enlarge the prevention perimeter demand the stimulation of negotiation practices that associate political and technical difficulties. As an example of the latter we can indicate how to formulate proposals to improve the managerial aspects indicated in the analysis as contributing to the accident. In the former case, the difficulties refer to the adjustments of management policies and practices adopted by the companies such as attributing blame to a third party, thus excluding themselves from any responsibility on the process.

The enlargement of the intervention perimeter of prevention appears more easily able to support all or any type of a potentially accidentogenic aspect identified in the analysis and not exclusively in those that effectively participate in the accident in question.

\section{References}

[1] Santana VS, Araújo-Filho JB; Albuquerque-Oliveira PR, Barbosa-Branco A. Acidentes de trabalho: custos previdenciários e dias de trabalho perdidos. Rev. Saúde Pública 2006; 40(6): 1004-1012.

[2] Almeida IM; Vilela RAV. Modelo de Análise e Prevenção de Acidente de Trabalho. Piracicaba: Cerest; 2010. Available in 05/20/2011 in http://www.moodle.fmb.unesp.br/course/view.php?id $=52$

[3] Cordeiro R; Vilela RAG et. all. O sistema de vigilância de acidentes de Trabalho de Piracicaba, São Paulo, Brasil. Cad. Saúde Pública, Rio de Janeiro, 21(5):1574-1583, 2005. 
[3] Guerin F et all. Compreender o trabalho para transformálo. A practice da Ergonomics. São Paulo: Edgard Blücher e Fundação Vanzolini; 2001.

[4] Llory M. Acidentes Industriais: O custo do silêncio. Rio de Janeiro, MultiMais Editorial, 1999.
[5] Reason JT. Human error. 2nd Ed. Cambridge University Press. 1999. 250p. 